\title{
MUJERES CAMPESINAS Y CONSTRUCCIÓN DE PAZ TERRITORIAL EN COLOMBIA: EL CASO DE LA ASOCIACIÓN CAMPESINA DEL VALLE DEL RÍO CIMITARRA (ACVC)*
}

\author{
PEASANT WOMEN AND CONSTRUCTION OF TERRITORIAL PEACE IN \\ COLOMBIA: THE CASE OF THE PEASANT ASSOCIATION OF THE VALLEY \\ OF THE CIMITARRA RIVER (ACVC for its acronym in Spanish)
}

Juan Sebastián Correa-Delgado**

\section{Resumen}

Objetivo. Contextualizar el trabajo organizativo de la ACVC con mujeres campesinas de la región (1996-2017) y describir expectativas y potencialidades de paz de las mujeres campesinas lideresas frente a la implementación de los acuerdos de La Habana. Metodología. Investigación de carácter cualitativo con enfoque de memoria histórica. Resultados. Se reconoce el trabajo organizativo realizado por la ACVC con las mujeres campesinas mediante encuentros, talleres y espacios de formación. Se evidencian potencialidades frente al Acuerdo Final de Paz mediante la Coordinadora de Mujeres del Valle del río Cimitarra como propuesta de paz territorial construida desde el Magdalena Medio. Conclusión. En el proceso de memoria colectiva realizado con lideresas de la ACVC se evidenciaron las expectativas que tienen frente a la implementación del Acuerdo Final de Paz en su territorio, desde la perspectiva de satisfacción de derechos sociales, económicos y políticos, afectados por el abandono estatal que predomina en el campo colombiano.

Palabras clave: memoria histórica, trabajo organizativo, mujeres campesinas, paz territorial.

\begin{abstract}
Objective. To contextualize the ACVC organizational work with peasant women in the region (19962017) and to describe expectations and peace potentiality of women leaders in the face of the implementation of the Havana agreements. Methodology. Qualitative research with a historical memory approach. Results. The organizational work carried out by the ACVC with peasant women through meetings, workshops and training spaces is recognized. Potential evidence is evident in the face of the Final Peace Agreement through the Cimitarra River Valley Women's Coordinator, as a territorial peace proposal built from the Magdalena Medio region. Conclusion. In the process of collective memory carried out with the ACVC leaders, the expectations they have regarding the implementation of the Final Peace Agreement in their territory were evidenced from the perspective of satisfaction of social, economic and political rights, affected by the abandonment of the State that predominates in the Colombian countryside.
\end{abstract}

Key words: historical memory, organizational work, peasant women, territorial peace.

\footnotetext{
* El presente artículo es resultado del trabajo de grado para obtener el título de trabajador social en la modalidad pasantía de investigación denominada "Desde las voces de las mujeres campesinas reconstruimos la historia y construimos paz: memoria histórica con las lideresas de la Asociación Campesina del Valle del río Cimitarra" llevada a cabo en el marco del proyecto de investigación "Reconstrucción de la memoria histórica de la Asociación Campesina del Valle del río Cimitarra ACVC desde un enfoque de género”, financiado por Colciencias en el marco de la convocatoria 745 de 2016 y ejecutado por el Grupo Población, Ambiente y Desarrollo-GPAD de la Universidad Industrial de Santander, Colombia.

** Universidad Industrial de Santander. Bucaramanga, Colombia. E-mail: sebaskorrea5@hotmail.com

(D) orcid.org/0000-0002-5780-3205 Google Scholar
} 


\section{Introducción}

En el contexto colombiano la discusión sobre la importancia del ejercicio de la memoria histórica no se ha quedado atrás dado que vive un conflicto armado interno desde hace más de 50 años a causa de factores como "la persistencia del problema agrario; la irrupción y la propagación del narcotráfico; las limitaciones y posibilidades de la participación política; las influencias y presiones del contexto internacional; la fragmentación institucional y territorial del Estado” (GMH, 2013, p. 111). Como consecuencia, las confrontaciones armadas entre fuerza pública, paramilitares y guerrillas han dejado más de ocho millones de víctimas, afectando a individuos, familias, comunidades y colectividades no combatientes, entre ellos a las mujeres (Registro Único de Víctimas, 2019). En el Magdalena Medio las mujeres campesinas han sido víctimas tanto por los impactos sociales, económicos y medioambientales de las actividades extractivas y agroindustriales como de "la persecución, barbarie y tortura originada por su movilización para reclamar derechos y oponerse a las violencias existentes” (Defensoría del Pueblo, 2014, p. 161).

La región del Magdalena Medio colombiano se ha caracterizado por su alto nivel de conflictividad debido a la riqueza en recursos naturales que tiene este territorio, generando dinámicas de movilización social en torno a tres aspectos: la colonización, el conflicto agrario sin resolverse y la resistencia, convirtiéndola en uno de los epicentros de conflictividad política y social, expresada en el surgimiento de la Unión Sindical Obrera (USO), las guerrillas del ELN en los años 60, fracciones del EPL y las FARC (Cely, 2015).

En los años 80 y 90 el Magdalena Medio vivió altas dinámicas de conflictividad social, lo cual generó una respuesta de guerra sucia y despiadada frente a los sectores políticos presentes en la región, esta persecución política fue gestada por grupos paramilitares quienes centraron como objetivo de su genocidio político a organizaciones de carácter popular y sus líderes, donde grupos como la ANUC, la Coordinadora Campesina del Magdalena Medio y la UP desaparecieron como movimiento político debido a las masacres y asesinatos (Suárez, 2017).

Es en este contexto cuando surge la Asociación Campesina delValle del río Cimitarra (ACVC) entre 1996 y 1998 dadas las marchas campesinas que se dieron en Barrancabermeja como respuesta a la violencia generada por los actores armados en la zona y el abandono estatal que históricamente ha vivido el campesinado colombiano, los campesinos de los municipios de Cantagallo, Remedios y Yondó reunidos en sus respectivas JAC decidieron hacer en el segundo semestre de 1996 una gran marcha campesina a Barrancabermeja y permanecer ocupando los principales parques o plazas de la ciudad en busca de diálogos regionales y nacionales (Silva-Prada, 2012).

Es así como la ACVC se constituye como una organización social de base campesina que busca la defensa de la permanencia del campesinado en el territorio y los derechos humanos en el 
marco del conflicto armado colombiano, mediante la figura jurídica de la zona de reserva campesina establecida en la ley 160 de 1994 (ACVC, s.f). La zona de reserva campesina ZRC- fue declarada en 2002 mediante la resolución 028 del 10 de diciembre, teniendo en cuenta el Plan de Desarrollo Sostenible de la Asociación Campesina del Valle del río Cimitarra, estipulando una extensión de 184 mil hectáreas donde habitan cerca de 36.000 campesinos y campesinas del Magdalena Medio colombiano (Cely, 2015). Sin embargo, en el gobierno del presidente Álvaro Uribe Vélez, la ACVC fue objeto de persecución política sistemática, la cual se manifestó en primera instancia con la suspensión de la ZRC mediante la resolución 046 del 10 de abril de 2003 del INCORA, el asesinato de varios de sus líderes y lideresas y la detención y estigmatización social de la Junta Directiva de la Asociación en 2007. A pesar de las dificultades presentadas, la asociación continuó con su propuesta de resistencia en el territorio, llevando a cabo proyectos de Derechos Humanos, soberanía alimentaria, vivienda, saneamiento básico, entre los que se destacan el proyecto de "aldea comunitaria Puerto Matilde” y la ganadería campesina de búfalos, que los llevaron a ganar el Premio Nacional de Paz en 2010 (Cely, 2015).

Durante los 21 años de existencia la ACVC ha generado espacios de participación política y productiva a través de encuentros, talleres, seminarios, escuelas, comités veredales de mujeres y actualmente la Coordinadora de Mujeres del Valle del río Cimitarra, donde las mujeres campesinas han jugado un papel fundamental en la defensa del territorio y los derechos humanos del campesinado. Teniendo en cuenta lo anterior, el presente artículo expone desde las voces de las lideresas de la ACVC, el trabajo organizativo desarrollado con las mujeres campesinas de la región, así como las expectativas y potencialidades frente a la implementación del acuerdo final.

\section{Feminismo campesino y popular, memoria histórica y paz}

El feminismo es un movimiento históricamente construido, local, mundial, social y político que posee un objetivo de emancipación y un contenido normativo, planteando como centro de su reflexión y acción la existencia de las mujeres como sujeto que se encuentra subordinado por las relaciones de género, por tanto su apuesta consiste en acabar con las relaciones de dominación, de discriminación sexual, buscando la liberación sexual, el reconocimiento de los derechos e intereses de las mujeres, así como transformar las estructuras institucionales y legales que permitan incluir una perspectiva de género (Dietz, 2003, p. 179). Sin embargo, las posturas que ha sumido este movimiento político y social se han visto permeadas por las diferentes corrientes teóricas que han abordado esta problemática en los últimos dos siglos.

En el caso de las mujeres campesinas de América Latina, las propuestas de reflexión política no han sido solo objeto de la academia sino que debido a las desigualdades presentes en esta región han surgido apuestas teóricas y políticas como el feminismo campesino y popular, apuesta gestada desde los movimientos sociales campesinos como la Coordinadora Latinoamericana 
de Organizaciones Campesina -Vía Campesina-CLOC-VC, la cual, según Etelvina Masioli, lideresa del movimiento de Mujeres Sin Tierra de Brasil, plantea la necesidad de la reflexión conjunta y articulada de los temas como "medioambiente, de los territorios, de la soberanía alimentaria, la agroecología, la construcción de otro modelo de sociedad y agricultura, no pueden estar separados" (Longo, 2016, p. 156).

Este trabajo de movilización política de la mujer campesina en América Latina llevó a la CLOC-VC, en el VI Congreso de la Coordinadora Latinoamérica de Organizaciones del Campo, realizado en abril de 2015 en Argentina, proponer en un pronunciamiento público las bases para el concepto del feminismo campesino y popular. Este concepto feminista emergente plantea que para lograr una igualdad sustantiva en las relaciones de género es necesario una transformación económica-estructural del sistema capitalista, ya que este impone lógicas de doble explotación, al respecto sostienen CLOC-vía campesina (2015):

Luchamos por la destrucción de todas las formas de dominación y
explotación de este modelo nefasto. Del mismo modo, sostenemos que,
en la lucha por construir una nueva sociedad, más allá del capitalismo,
se deben abordar las desigualdades de género (...). Las mujeres
experimentan rutinariamente una doble dominación: la explotación de
clase y la opresión de género.Y cuando las mujeres participan en la lucha
y se organizan en movimientos, ya sea mixtos o de mujeres llevan estas
determinaciones socialmente construidas. (pp. 2-3)

Por tanto, esta apuesta política feminista concibe al capitalismo y el patriarcado directamente relacionados donde todo se convierte en mercancía, analizando las consecuencias históricas de la división social del trabajo ligada a la división social base de la desigualdad de género en el campesinado (Cloc-Vía Campesina, 2015). Es así, como el movimiento de mujeres campesinas adoptó en 2010 en Quito, Ecuador, la consigna “sin feminismo, no hay socialismo" planteando una apuesta de transformación no solo de las relaciones de género sino de las estructuras políticas y económicas con la abolición del capitalismo.

En este marco el feminismo campesino y popular se plantea como una propuesta política reflexiva que, desde una perspectiva de la interseccionalidad, que permite develar las desigualdades de género construidas históricamente en el ámbito económico, social y cultural que reproducen violencias que afectan a las mujeres campesinas, las cuales se ven intensificadas en contextos de guerra como el colombiano. En este sentido, la memoria se convierte en una herramienta política fundamental para esclarecer los hechos sucedidos en el marco de las confrontaciones armadas, en el caso de grupos excluidos por las dinámicas violentas, así lo afirman Jelin (2002), quien expresa que: 
La memoria tiene entonces un papel altamente significativo, como mecanismo cultural para fortalecer el sentido de pertenencia a grupos o comunidades. A menudo, especialmente en el caso de grupos oprimidos, silenciados y discriminados, la referencia a un pasado común permite construir sentimientos de autovaloración y mayor confianza en uno/a mismo/a y en el grupo. (pp. 9-10)

Por ello, se plantea la necesidad de abordar la memoria histórica desde una perspectiva de género con mujeres, ya que históricamente se han excluido del ámbito público debido a los roles que se han construido socialmente que limitan su acción a los espacios privados. Por tanto, las mujeres campesinas tienen formas particulares de recordar y silenciar, aun cuando en conflictos armados como el colombiano la mayoría de las sobrevivientes sean mujeres, son pocos los relatos que le otorgan un lugar central y que hacen la labor al entender desde donde recuerdan y se expresan (CNRR y GMH, 2011, p. 55). Es así como es necesario pensar la memoria histórica desde la diversidad y la interseccionalidad que representa ser mujer, campesina y lideresa de una organización social de base en el marco del conflicto armado colombiano, ya que las experiencias de las mujeres en la guerra no son homogéneas y varían de acuerdo con su condición de género, ideología, religión, política, clase, etnia, raza, generación y diferencias regionales (CNRR y GMH, 2011, p. 58).

Por tanto, es necesario plantear un uso de la memoria que permita no sólo recordar y visibilizar colectivamente aquellos hechos traumáticos ocurridos en el marco de las confrontaciones armadas, desde una postura pasiva de las víctimas, sino desde allí plantear propuestas y potencialidades frente a la construcción de paz de acuerdo con estos hechos pasados. Al respecto, Todorov (2000) propone el concepto de uso ejemplar de la memoria, el cual "permite utilizar el pasado con vista al presente, aprovechar las lecciones de las injusticias sufridas para luchar contra las que se producen hoy en día y separarse del yo para ir hacia el otro” (p. 32). De esta manera, no solo se recuerda por el pasado mismo, sino en búsqueda de sentido en el presente, lo cual resulta fundamental en contextos de construcción de paz en países donde se busca salida negociada a conflictos armados, donde procesos de memoria desde una postura política con aquellos sectores excluidos juegan un papel fundamental en la apertura democrática y la diversidad de posturas frente al concepto de paz.

La paz es una práctica universal. Los inicios de los estudios de este concepto polisémico se dan en el contexto de la primera y segunda guerra mundial, donde surge la necesidad de estudiar científicamente este fenómeno, dado que la paz era entendida desde la ausencia de guerra (Guzmán, 2009). Frente a esta discusión, el noruego Galtung (1996) afirma que "paz debe entenderse como la ausencia o reducción de todo tipo de violencias” (p. 9), abriendo la posibilidad de diferenciar los diferentes tipos de violencias entre las que se encuentra la directa, estructural y cultural, al respecto Jiménez (2012) define: 


\begin{abstract}
Violencia directa es la realización de un emisor o actor intencionado (en concreto, una persona), y quien sufre es un ser dañado o herido física o mentalmente (...). Violencia estructural, se manifiesta cuando no hay un emisor o una persona concreta que haya efectuado el acto de violencia (...). Violencia cultural, se refiere a los aspectos de la cultura que aportan una legitimidad a la utilización del arte, religión, ciencia, derecho, ideología, medios de comunicación, educación, que vienen a violentar la vida. (p. 45)
\end{abstract}

Por otro lado, en Colombia en el marco del proceso de paz se promulga el concepto de paz territorial, acuñado por el ex alto comisionado para la paz Sergio Jaramillo. Sin embargo, han surgido voces críticas a esta postura, como la desarrollada por Sergio de Zubiría, quien plantea un concepto crítico sobre la paz territorial que rompe con la tradición liberal (Fontan, 2013) que concibe este proceso desde una postura de aterrizaje impuesto desde las instituciones centralizadas a los territorios, concibiendo a los grupos, poblaciones y comunidades como sujetos pasivos de atención, al contrario "se trata de una concepción de la planeación participativa "desde abajo", desde la sabiduría plebeya territorial, que controle el centralismo y la tecnocracia, respetando las agendas territoriales históricas” (De Zubiría, 2017, p. 9).

En este sentido, en Colombia se resaltan las propuestas de paz gestadas desde las comunidades y territorios, entre la que está el concepto de iniciativas de paz, base desde la cual, según Hernández (2004):

\begin{abstract}
Pueden ser entendidas como procesos organizativos en torno de diversos valores, constitutivos de la paz y la democracia, que son generados y jalonados por comunidades o conjuntamente por estas y las iglesias, dentro del territorio común en el que residen. Surgen como respuesta organizada y sin recurso a la violencia frente al impacto del conflicto armado y/o diversas expresiones de violencia estructural, y han contado generalmente con el apoyo de iglesias, ONG nacionales e internacionales y la cooperación internacional. (p. 22)
\end{abstract}

\title{
Aspectos metodológicos
}

La investigación desarrollada es de carácter cualitativo con enfoque de memoria histórica, por tanto se trabajó de manera colectiva con fuentes orales que permitiera reconstruir los hechos del pasado que perviven en la memoria de las mujeres lideresas de la ACVC, teniendo en cuenta que, como plantea Halbwachs (1968), "la historia vivida se distingue de la historia escrita: tiene todo lo necesario para construir un marco vivo y natural en el que un pensamiento puede apoyarse para conservar y encontrar la imagen de su pasado” (p. 210). 
Es así como en las ciencias sociales, especialmente desde el pensamiento social crítico latinoamericano, se ha gestado la postura de construir historia desde los de abajo que según Torres (2014), "es aquella que reconoce el protagonismo de los sectores populares en la historia-materia y también su potencial como sujetos de conocimiento histórico” (p. 90). Esto permite pensar la memoria histórica desde las mujeres campesinas de la ACVC como sujetos sociales en el marco del conflicto armado colombiano.

Por tanto, el proceso metodológico se estructuró teniendo en cuenta cuatro fases: preparatoria, de trabajo de campo, analítica e informativa (Rodríguez, Lorenzo y Herrera, 2005). Al respecto, se tomaron como eje de análisis, en primera instancia, el trabajo organizativo con las mujeres de la ACVC, seguidamente los repertorios de violencia vividos por las mujeres campesinas a causa del conflicto armado y finalmente las expectativas y potencialidades frente a la implementación del Acuerdo Final de Paz. Entre las herramientas de recolección y técnicas de investigación social utilizadas se estuvo en siete actividades de participación política de la asociación campesina en calidad de observadores, a su vez se llevaron cabo dos talleres de memoria colectivos, en los que participaron en promedio 15 mujeres lideresas, teniendo en cuenta por lo menos cinco años de antigüedad en la asociación. En estas jornadas se usaron herramientas como la línea de tiempo, cartografía social y telaraña de memoria, tomando como referencia el material de apoyo "Recordar y narrar el conflicto" (CNM y UBC, 2013). Por otro lado, se realizaron dos entrevistas individuales y dos colectivas a mujeres lideresas de la ACVC. Los instrumentos de recolección de información fueron diseñados con el apoyo del equipo profesional del Grupo en Población Ambiente y Desarrollo-GPAD.

En cuanto a las consideraciones éticas, las mujeres participantes del proyecto de investigación fueron informadas acerca de los objetivos, para tal fin se diseñó un consentimiento informado que permitió la participación voluntaria de las mujeres lideresas, a su vez para evitar situaciones que pusieran en riesgo a las participantes la investigación se manejó el principio de confidencialidad de la identidad. Para el análisis y organización de las entrevistas transcritas se destaca el uso del software especializado Atlas Ti ${ }^{\circledR}$ versión 6.2, es importante mencionar que los hallazgos de investigación fueron validados con la comunidad participante. 


\section{Resultados}

\section{La Asociación Campesina del Valle del río Cimitarra y el trabajo organizativo con las mujeres campesinas de la región}

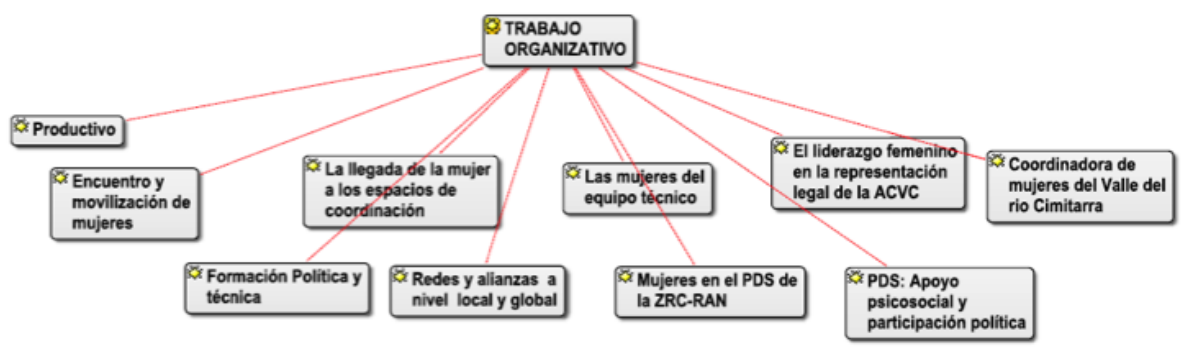

Gráfica 1. Categorías emergentes trabajo organizativo. Elaborado con ATLAS.ti ® Versión 6.2 Fuente: elaboración propia.

El trabajo que ha desarrollado la ACVC con las mujeres campesinas de la ZRC se ha caracterizado en su primer momento por su énfasis en el trabajo productivo campesino relacionado con el cuidado de animales y cultivo de huertas para el sustento familiar, los cuales fueron impulsados por la figura de participación comunitaria de los comités veredales de mujeres, en el marco de los proyectos de defensa del territorio mediante la figura de las zonas de desarrollo integral. Sin embargo, entre 2004 y 2005 se consolidaron los comités veredales de mujeres, especialmente en la seccional Sur de Bolívar, donde las mujeres participaron en proyectos dirigidos al ámbito productivo alimenticio, concibiendo así a las mujeres campesinas como las responsables de proveer los alimentos de la familia en el ámbito campesino, al respecto, según la FAO (como se citó en Korol, 2016), "entre un 60 y un $80 \%$ de la producción de alimentos en los países del Sur, recae en las mujeres, un 50\% a nivel mundial” (p. 92).

Por otro lado, la difícil situación que vivió el Magdalena Medio por cuenta del conflicto armado entre 2002-2010 y la violencia estructural del gobierno colombiano, conllevó a las mujeres de la ACVC a desarrollar espacios de encuentro y movilización como el I Encuentro Regional de las Mujeres del Magdalena medio el 25 de marzo de 2006 en la ciudad de Barrancabermeja, donde participaron diversas organizaciones políticas y sociales y mujeres campesinas de la región (Proceso de Mujeres del Magdalena Medio, 2006).

Es en el marco del año 2006, cuando la ACVC comienza a promover espacios de formación política y técnica en temas equidad de género, el papel de la mujer en la historia, participación política de la mujer, derechos humanos y liderazgo, salud sexual y reproductiva y violencia contra la mujer desarrollándose talleres en diferentes veredas y seccionales (ACVC, 2006). Los procesos de formación política y técnica son una constante en la asociación campesina y han 
generado el empoderamiento de las mujeres en cuanto a sus derechos y labores productivas, al respecto una de las lideresas sostiene:

\begin{abstract}
Tenemos muchas cosas que nos ha enseñado esta organización, nos ha educado a alguna parte para uno poder enseñar a nuestra familia, nuestros hijos, nuestros amigos, nuestros vecinos y es bastante importante porque hemos aprendido demasiadas cosas. (Taller Hechos de violencia (0) Mujeres_Cantagallo, comunicación personal, 27, agosto, 2017)
\end{abstract}

Sin embargo, a pesar de los aportes de la ACVC a los campesinos de la región, en el 2007 se da una persecución sistemática por parte del gobierno de Álvaro Uribe Vélez con la detención de siete dirigentes de la ACVC, sindicados por el delito de rebelión (ACVC, 2009). Esta situación genera la llegada de una mujer a los espacios de coordinación de la asociación, Irene Ramírez quien asume la responsabilidad de ocupar el cargo en enero de 2008 en la coordinación de la oficina de la ACVC en Barrancabermeja (Pinto, 2011).

Es así, como para Irene Ramírez asumir la coordinación de la oficina de la ACVC no fue fácil, debido que pasó del ámbito privado y rural en la vereda Puerto Matilde, donde desarrollaba actividades relacionadas al tema productivo, al ámbito público urbano de representación de la Asociación en la oficina de Barrancabermeja, al respecto:

\begin{abstract}
Ya que la esfera pública, y especialmente la política, según esta división de roles, está en manos de los hombres, que son quienes toman decisiones que afectan o involucran a todos los géneros. Mientras tanto, la reproducción de la vida a través del trabajo doméstico, es considerada actividad de las mujeres. (Korol, 2016, pp. 98-99)
\end{abstract}

Con el fin de visibilizar la difícil situación de la ACVC y consolidar redes y alianza a nivel local y global en el proceso de las mujeres campesinas, la organización empezó a participar en espacios académicos y políticos que permitieran afianzar redes de apoyo, ya que "la promoción de derechos humanos y cooperación internacional ha reforzado formas de resistencia civil campesina y ha significado un límite al uso extralimitado de la violencia, que actores militares y paramilitares históricamente han ejercido sobre el campesinado" (Silva, 2011, pp. 144-145). De esta manera, Irene Ramírez llevó a cabo una gira por Europa visitando países como Italia, Alemania, Suiza y Bélgica, con el apoyo de brigadas internacionales de paz - PBI- donde pudo visibilizar frente a diferentes líderes y organizaciones la difícil situación que pasaba la ACVC, debido a la continuación de la suspensión de la Zona de Reserva Campesina, la estigmatización del proceso organizativo y los 16 casos de falsos positivos en la región (Páez, 2010). 
En el marco de estas redes y alianzas locales, la asociación mediante el equipo técnico, vincula a estudiantes voluntarios y profesionales quienes ponen a disposición sus conocimientos a la organización de manera gratuita, al aportar acciones direccionadas a la ejecución de los ejes temáticos del plan de desarrollo sostenible (Páez, 2016). Esto permitió la vinculación en 2009, la llegada de mujeres en proceso de formación profesional aportando al trabajo organizativo de la ACVC una mirada externa y estructural-interna de la situación por las campesinas en la región, logrando la inclusión en el sector 8 Mujer y Género del PDS, que reconoce las dificultades que presentan las campesinas por su condición de mujer en la región en plan de desarrollo sostenible de la ZRC, 2012-2022 (ACVC, 2013).

Es así como, teniendo en cuenta las necesidades expresadas por la mujeres de las ZRC del valle del río Cimitarra, el Plan de Desarrollo Sostenible 2012-2022 y el escenario de construcción de paz de cara a la implementación de los acuerdos de La Habana, los días 24 y 25 de agosto de 2017 se realizó el I Encuentro de Mujeres de la ZRC en el municipio de Cantagallo, donde participaron más de 200 mujeres de la región y delegados de instituciones regionales y nacionales, académicos y algunos invitados internacionales (ACVC, 2017). En el cierre del evento se conformó la Coordinadora de mujeres de la ZRC del valle del río Cimitarra, como una instancia que busca promover la participación de las mujeres, como se establece en el plan de desarrollo sostenible de cara a la implementación de los acuerdos de La Habana en la región, destacando así el papel histórico que han jugado las mujeres y grupos excluidos en la construcción de paz en Colombia (Ibarra, 2007, p. 84).

Finalmente, es de resaltar que el trabajo organizativo de la ACVC con las mujeres campesinas de la ZRC no es un tema reciente ni coyuntural, debido a que desde la década pasada diferentes personas de la ACVC han impulsado y promovido la participación de las campesinas en espacios de decisión, así como visibilizado su condición mediante talleres, escuelas, eventos, comités que han permitido la formación política de las mujeres campesinas del Magdalena Medio colombiano.

\section{Expectativas de las lideresas campesinas frente a la implementación de los acuerdos de La Habana}




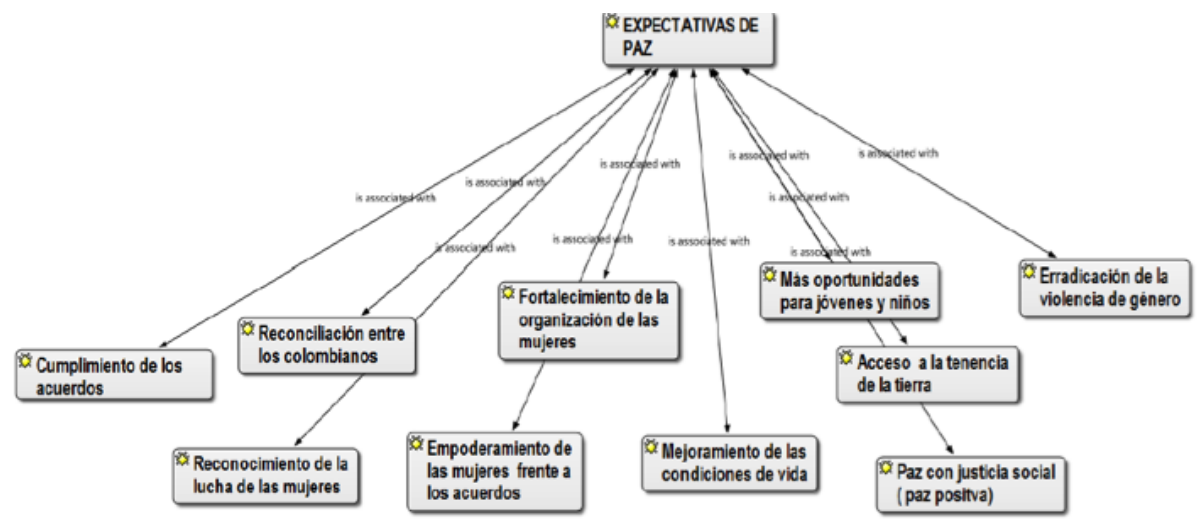

Gráfico 2. Categorías emergentes expectativas de paz. Elaborado con ATLAS.ti ${ }^{\circledR}$ Versión 6.2 Fuente: elaboración propia.

La implementación de los acuerdos de La Habana en regiones como el Magdalena Medio ha generado expectativas de futuro y de cambio en la mejora de las condiciones sociales y económicas en las poblaciones que se vieron afectadas por el conflicto armado. En cuanto a la implementación de los acuerdos en la ZRC del Valle del río Cimitarra las mujeres lideresas de las ACVC rescatan la importancia de este proceso de paz, sin embargo, hacen énfasis en la importancia del cumplimiento de los mismos, esperando el reconocimiento de sus derechos económicos, políticos y sociales, buscando superar la violencia estructural que viven en el campo que permita mejorar sus condiciones de vida y las de sus familiares y cercanos. Asimismo, las lideresas esperan que este escenario permita el fortalecimiento del trabajo organizativo con las mujeres campesinas de la región, que permita develar la violencia cultural que reproduce las relaciones de desigualdad de género, teniendo en cuenta las diversas violencias que afectan a las campesinas del Magdalena Medio, el impacto del conflicto armado y de diversas expresiones de violencia estructural, la estigmatización, negación de oportunidades y derechos, marginalidad, autoritarismo del cual ha sido víctima la ACVC (Hernández, 2004).

Una exigencia reiterativa en las expectativas frente a la paz es el cumplimiento de los acuerdos en los territorios, debido a que, a pesar del cese de las hostilidades entre las FARC y el ejército, aún se presentan dinámicas de violencia directa debido a que persisten asesinatos en algunas zonas tal como lo afirma una lideresa: "Bueno, pero para mí que se cumpla de verdad ese acuerdo que el gobierno porque la verdad es que todavía han dicho que ya está cumplido, pero eso no se ha cumplido, ha habido muchas muertes en varios pueblos" (Taller Paz_San Lorenzo_Mujeres, comunicación personal, 10 de noviembre de 2017).

Por otro lado, las expectativas de paz planteadas por las mujeres lideresas, frente a la implementación de los acuerdos en la ZRC, se relacionan constantemente con mejoramiento 
de sus condiciones de vida y los derechos económicos y sociales violentados históricamente por el Estado colombiano, así lo sostiene una lideresa campesina: "Nosotros tenemos derecho a educación salud y vivienda digna. Necesitamos centros de acopio para vender y comercializar como campesinos. Queremos que el gobierno se siente y piense resolverles los problemas a los campesinos en el campo" (Relatoría Expectativas de Paz Cantagallo, comunicación personal, 27 de agosto de 2017).

Al respecto, hay que resaltar que las mujeres campesinas en el país se han visto afectadas por las condiciones precarias del campo colombiano y faltas de garantías de producción agrícola, por lo cual recurren a productos de mejor rentabilidad como la hoja de coca (Zuluaga como se citó en Korol, 2016). Las expectativas de paz expresadas plantean un concepto que va más allá del cese de las hostilidades armadas en los territorios, donde se hace énfasis en las condiciones sociales que viven las campesinas, reivindicando la paz pero con justicia social. Por tanto, las expectativas planteadas pueden entenderse desde el concepto de paz positiva, el cual se relaciona con "el desarrollo de las potencialidades humanas encaminadas a la satisfacción de necesidades básicas” (Guzmán, 2009, p. 64), en el caso de las mujeres campesinas la exigencia del derecho a la salud, la educación, la tierra, garantías de producción y distribución de sus productos agrícolas:

[...] a través de estas negociaciones con las FARC tengamos muchas ayudas a las comunidades, sí, estudio, vías, educación, salud, centros de acopio para uno producir la tierra, los que tengamos los que tenemos todavía estando en el campo, porque muchas personas se han ido hacia el pueblo, así como han dicho las compañeras de que tengan derecho de nuevamente de volver a sus tierras, para volver a cultivar la comida, la agricultura. (Taller Paz_San Lorenzo_Mujeres, comunicación personal, 10 de noviembre de 2017)

El acceso a la titularidad de la tierra es un problema presente en las mujeres campesinas colombianas, debido al imaginario construido que en quien debe recaer esta responsabilidad es en el jefe de la familia, que en su mayoría se consideran los hombres.

El derecho de acceso a la tierra es planteado por las mujeres campesinas como una de las expectativas de paz fundamentales para lograr la mejora de sus condiciones de vida, además permite potenciar el arraigo e identidad de las lideresas campesinas, convierte un elemento central económico que posibilita la soberanía y el derecho a decidir sobre sus vidas (Korol, 2016, p. 118).

De acuerdo con lo anterior, la violencia de género que viven las mujeres campesinas de la ACVC también hace parte de las expectativas que esperan que puedan ser abordadas en la 
Mujeres campesinas y construcción de paz territorial en Colombia: el caso de la asociación campesina del Valle del río Cimitarra (ACVC)

implementación del acuerdo de paz, por lo cual se reconoce la urgencia de construir la paz desde los territorios, aplicando un enfoque de género; al respecto afirman:

Bueno mis expectativas, es que se pueda garantizar que a las mujeres campesinas se les dé su reconocimiento que no haya violencia más en contra de las mujeres, que en estos acuerdos de paz, se pueda que el Estado pueda cumplir y que le pueda cumplir a las mujeres (...) Entonces una de nuestras expectativas y como organización garantizar un poco que las compañeras conozcan de sus derechos, pero que el estado también cumpla y que podamos todas las mujeres tener un reconocimiento y que podamos tener una vida digna. (Taller Paz_San Lorenzo_Mujeres, comunicación personal, 10 de noviembre de 2017)

Las expectativas de paz de las mujeres campesinas lideresas de las ACVC frente la implementación de los acuerdos de La Habana se conciben desde las experiencias, movilizaciones, acciones y diversos tipos de violencias que han vivido en su territorio, haciendo énfasis en la necesidad del cumplimiento de los acuerdos por parte del gobierno nacional, estableciendo que la paz no sólo implica el desarme de un grupo armado sino que, principalmente, se relaciona con el ejercicio de los derechos sociales, económicos y políticos de las mujeres campesinas y la búsqueda de una paz con justicia social, paz positiva (Galtung, 1996), que a su vez tenga en cuenta la violencia de género que viven cotidianamente en el ámbito campesino las mujeres en Colombia donde se construyen posturas reflexivas como el feminismo campesino y popular, ya que como afirma Duby Ordóñez, lideresa campesina del Comité de Integración del Macizo Colombiano, "vivimos en un mundo machista, somos mujeres y además campesinas” (Agredo, 2016, p. 169).

\section{Potencialidades de las mujeres campesinas de la ACVC frente a la implementación de los acuerdos de La Habana}

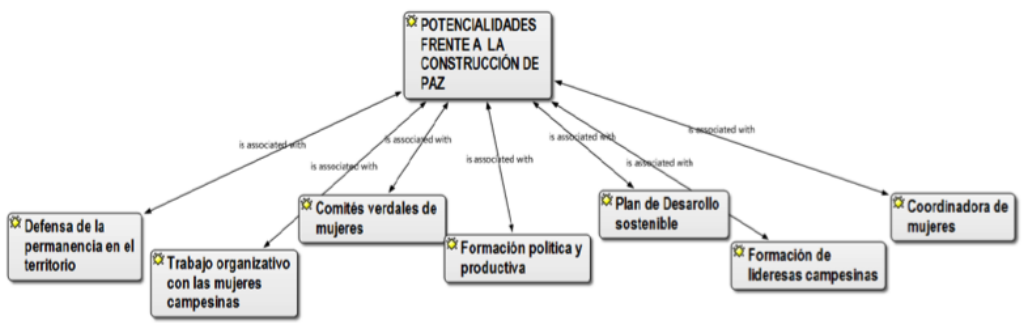

Gráfico 3. Categorías emergentes potencialidades frente a la implementación de los acuerdos de La Habana.

Fuente: elaboración propia 
La participación de la mujer campesina en la construcción de paz no es un tema reciente debido al auge del concepto de paz territorial que desarrolla el gobierno nacional, ya que se han venido dando en algunos territorios desde procesos colectivos, como es el caso de la ACVC que desde 2005 ha venido desarrollado un trabajo organizativo que busca potenciar la participación comunitaria de las mujeres campesinas, entre los que se destacan: comités veredales de mujeres, espacios de formación productiva y política (encuentros, seminarios, talleres), inclusión de proyectos dedicados a las mujeres rurales en el Plan de Desarrollo Sostenible 2012-2022, formación de lideresas en temas de género y agroecología y la creación de la coordinadora de mujeres del valle del río Cimitarra. Las potencialidades reconocidas en las mujeres lideresas de la ACVC se refieren a aspectos como: defensa de la permanencia del territorio, trabajo organizativo con las mujeres campesinas, comités veredales de mujeres, formación política y productiva, plan de desarrollo sostenible, formación de lideresas campesinas y coordinadora de mujeres.

Así pues, los espacios de formación han gestado en la ACVC liderazgos en las mujeres campesinas, quienes se reconocen como constructoras de paz desde sus realidades más cercanas, de cara a la implementación de los acuerdos de La Habana, así lo afirma:

\begin{abstract}
Mi compromiso es organizar a las mujeres de mi comunidad y a las cercanas de mi corregimiento, es un reto más para mi vida (...). Somos las mujeres las que tenemos que ponerle la dirección a este proceso. Este proceso de paz no es solo que se entregaran las armas, sino que significa que el gobierno nos reconozca los daños a los campesinos. Calladas nunca vamos a poder nada. Las mujeres tenemos grandes trabajos, grandes retos y mucho compromiso. (Relatoría Expectativas de paz Cantagallo, comunicación personal, 27 de agosto de 2017)
\end{abstract}

En la asociación campesina, mediante las redes y alianzas establecidas con organizaciones sociales nacionales e internacionales, algunas mujeres campesinas han podido participar de espacios de formación política en lo relacionado al tema de género, donde se destacan la participación de mujeres lideresas campesinas en espacios de la CLOC-VC, trabajando la postura teórica del feminismo campesino y popular, lo cual ha conllevado a estas lideresas a propiciar espacios de formación interna en la ACVC, y donde los líderes campesinos también participan buscando aclarar el tema de género.

La coordinadora de mujeres del valle del río Cimitarra se plantea como una propuesta de paz territorial de las mujeres campesinas de la ACVC, quienes mediante la participación comunitaria en los comités veredales de mujeres y juntas de acción comunal, las mujeres puedan exigir y proponer mecanismos para defender sus derechos contemplados en el acuerdo final de paz, al respecto una lideresa afirma:

Hay una fortaleza que es la firma de los acuerdos que las mujeres 


\begin{abstract}
debemos empoderarnos, también hay mucha preocupación porque hay un debilitamiento del proceso y no hay un cumplimiento por parte del Estado para que sean efectivos esos acuerdos y garantizar nuestros derechos. Esos acuerdos son del pueblo colombiano, nosotras mismas tenemos que empoderarnos. Eso que hicimos con la coordinadora, eso hace parte de la implementación de los acuerdos. Uno lo que visiona es ver un país con garantía, con salud, educación con vivienda digna para las mujeres, eso se tiene que dar, pero si el Estado cumple. (Relatoría Expectativas de paz Cantagallo, comunicación personal, 27 de agosto de 2017)
\end{abstract}

En este sentido, la propuesta de la creación coordinadora de mujeres de la ACVC nace con el fin de reconocer y reivindicar el trabajo de las mujeres campesinas en la región, buscando exigir mecanismos que permitan la exigibilidad de derechos y no medidas pasivas-asistencialistas que reproducen la violencia estructural, al respecto una lideresa afirma:

\begin{abstract}
Ahí vamos a estar dando la pelea, dándoles la pelea al estado colombiano, a sus políticas de asistencialismo porque esas políticas de asistencialismo nos ha perjudicado mucho a nosotras las mujeres, esos programitas que el Estado tiene, que no beneficia, que no empodera a las mujeres, que nos somete a unas migajas, que en ese sentido la coordinadora lo que busca es un empoderamiento de la mujer y que la mujer conozca sus derechos y que las mujeres sean las que den la lucha por defender su territorio. (Entrevista individual_mujer lideresa Barrancabermeja, comunicación personal, 26 de enero de 2018)
\end{abstract}

Por tanto, la construcción de paz desde los territorios no debe concebirse desde la perspectiva centralista que concibe los derechos como programas asistencialistas pasivos, donde se desconoce la potencialidad como actoras políticas de las mujeres campesinas, en consecuencia es necesario descolonizar el concepto de paz, lo cual implica reconocer que la paz ya existe localmente, que no tiene que ser construida de acuerdo con los valores y el entendimiento de quienes no son propios de ese entorno (Fontan, 2013), donde en el caso de las mujeres campesinas de la ACVC, la institucionalidad colombiana reconozca sus aportes a la construcción de paz desde el Magdalena Medio.

Es así como la Coordinadora de Mujeres se posiciona, como un espacio de interlocución y defensa de los derechos de las mujeres campesinas, donde no son las entidades gubernamentales quienes imponen las agendas para construir la paz territorial, al respecto De Zubiría (2017) sostiene: "Se trata de una concepción de la planeación participativa "desde abajo", desde la sabiduría plebeya territorial, que controle el centralismo y la tecnocracia, respetando las 
agendas territoriales históricas" (p. 9). Lo planteado en el PDS 2012-2022 que se desarrolla en los comités veredales y la coordinadora de mujeres, permiten la construcción una paz de los territorios que reconozca las agendas construidas por las mujeres campesinas del valle del río Cimitarra, asumiendo la autodeterminación democrática de su destino (De Zubiría, 2016).

\section{Conclusiones}

En el actual escenario de construcción de paz que vive Colombia, resulta fundamental reconstruir el pasado vivido por cuenta de las poblaciones afectadas por el conflicto armado, reconociendo el papel que han ocupado las mujeres campesinas en medio de la guerra. Por tanto, pensar procesos de reconstrucción de memoria histórica desde las mujeres campesinas lideresas de la ACVC conlleva a reconocer cómo, desde sus veredas y comunidades, le aportan a la construcción de paz territorial desde sus conocimientos y saberes.

En primera instancia, se evidencia la existencia de un trabajo organizativo con las mujeres de la ACVC desde hace más de 10 años, donde la asociación campesina ha dado debates internos frente a la manera de promover la participación comunitaria de las mujeres campesinas, donde se destaca la existencia de comités de mujeres veredales, desde los cuales se apoyan proyectos productivos y se generan espacios de formación política y técnica para las mujeres. A su vez, es de resaltar que la asociación campesina actualmente, debido a las alianzas y redes construidas se encuentran desarrollando un enfoque de género, adoptándolo una postura feminista que se viene trabajando desde las organizaciones que integran la Coordinadora Latinoamericana de Organizaciones del campo, Vía Campesina, la cual se denomina feminismos campesino y popular.

Al respecto, es de resaltar que el presente ejercicio de memoria histórica espera aportar desde la reflexión académica, al debate frente a los procesos de verdad, construcción de paz y reparación en Colombia gestados desde las campesinas con el enfoque de memoria histórica adoptado, visibilizando el papel que ocupan las mujeres lideresas del Magdalena medio en la construcción de paz desde los territorios en organizaciones como la ACVC. Al respecto, en los trabajos realizados sobre paz y mujeres rurales en Colombia, según Bautista y Bedoya (2017):

La teorización sobre el tema de paz para el análisis del papel de las mujeres en el caso colombiano aún es precaria. Tal situación plantea como reto la necesidad de discutir si este cuerpo conceptual resulta suficiente para comprender la realidad de las mujeres rurales (¿campesinas?). (p. 143)

Así pues, la academia colombiana debe aportar a la reflexión sobre el papel fundamental que ocupan las mujeres campesinas en la construcción de paz desde los territorios y regiones, donde debido a las relaciones de género desiguales hegemónicas en los contextos rurales 
latinoamericanos, se viene gestando la propuesta del feminismo campesino y popular, propuesta que plantea la erradicación de todo tipo de explotación y dominación que viven las mujeres campesinas por cuenta de las relaciones desiguales de género, pero también en el marco del sistema capitalista contemporáneo con sus políticas neoliberales que reproduce lógicas de violencia estructural, con las que las más afectadas son las mujeres campesinas (Korol, 2016). Por ello, esta perspectiva feminista resignifica e incluye en su discurso político los temas de medioambiente de los territorios, la soberanía alimentaria y la agroecología, que conlleven a la construcción de otro modelo de sociedad y agricultura (CLOC-VC, 2015), desde regiones como el Magdalena Medio colombiano.

Las mujeres campesinas lideresas de la ACVC reconocen la importancia del acuerdo final en cuanto a la disminución de las confrontaciones armadas, sin embargo hacen énfasis en que la paz consiste en la satisfacción de sus derechos sociales, económicos y políticos, los cuales se han visto afectados por el abandono estatal que predomina en el campo colombiano, teniendo presente que es necesaria la movilización y la exigencia de sus derechos mediante mecanismos de participación comunitaria y democrática, por lo cual conciben la coordinadora de mujeres como potencialidad para aportar desde la ZRC una propuesta de paz territorial acorde a las realidades propias de sus veredas, municipios y poblaciones.

Por ello, iniciativas de paz de base social (Hernández, 2004) como la gestada por las mujeres campesinas de la ACVC, desde espacios de participación comunitaria como la Coordinadora de Mujeres del Valle del río Cimitarra, diversifican las acepciones frente al concepto imperante de paz territorial, institucional y liberal (De Zubiría, 2016) desarrollado por el gobierno nacional, el cual se caracteriza por una propuesta mecanicista de construcción de paz (Fontan, 2013), donde la propuesta de las mujeres campesinas de la ZRC se posiciona como una apuesta organizativa para la construcción de paz desde sus expectativas y potencialidades políticas.

Finalmente, la construcción de paz en Colombia debe descentralizar la discusión de los ámbitos académicos y élites políticas y dar paso a procesos de construcción de espacios de construcción de memoria, donde las poblaciones que más se han visto afectadas por el conflicto armado planteen sus posiciones que permitan el esclarecimiento del pasado, aportando desde el autoreconocimiento de los sucesos, una mirada hacia el presente y el futuro buscando garantías de no repetición en cuanto a los múltiples sucesos de violencias vividas (Jelin, 2002).

Por tanto, el proceso de memoria realizado con las mujeres campesinas lideresas de la ACVC, evidenció la esperanza existente en territorios como el Magdalena Medio, donde se espera que la implementación del acuerdo final genere condiciones poder construir la paz estable y duradera que tanto se anhela en Colombia. 


\section{Referencias}

ACVC. (Sin Fecha). “Qué es la ACVC?”. Recuperado de http://www.prensarural.org/acvc/ quesomos.htm

ACVC. (2006). Se dio inicio a la escuela de formación integral del proceso de mujeres de la ACVC. Recuperado de http:/ / prensarural.org/acvc/acvc20060623.htm.

ACVC. (2009). Estigmatización, judicialización y ejecuciones extrajudiciales en el valle del río Cimitarra. Recuperado de http://www.prensarural.org/spip/spip.php?article2489

ACVC. (2013). Cuadernillo de socialización de actualización del Plan de Desarrollo Sostenible ZRCVRC. Barrancabermeja, Colombia: Equipo Técnico y Agencia Prensa Rural.

ACVC. (2017). Se creó la Coordinadora de mujeres de la ZRC del Valle del río Cimitarra. Recuperado de http:/ / prensarural.org/spip/spip.php?article21979.

Agredo, E. (2016). Duby Ordóñez: “vivimos en un mundo machista, somos mujeres y además, campesinas”. En C. Korol. y G. Castro. (Comps), Feminismos Populares. Pedagogías Políticas (pp. 169-176). Bogotá: Colombia: La Fogata.

Bautista, S. y Bedoya, I. (2017). Mujer rural y construcción de paz: temas, problemas y desafíos. Revista Prospectiva, (24), 121-148. Recuperado de: http://revistaprospectiva. univalle.edu.co/index.php/prospectiva/article/view/4545

Cely, P. (2015). Memorias de movilización, organización y resistencia campesina en medio de la violencia sociopolítica y el conflicto armado interno en Colombia. El caso de la Asociación Campesina del Valle del río Cimitarra (ACVC). Aletheia, 15, 1-21. Recuperado de http:// www.aletheia.fahce. unlp.edu.ar/numeros/numero-10/pdfs / Cely. \%20Dossier. \%20 Articulo.pdf.

CLOC-Vía Campesina. (2015). VI Congreso de la Cloc-Vía Campesina Propuesta de texto para el debate en la Asamblea de Mujeres. Recuperado de https: / / viacampesina.org/es/feminismocampesino-y-popular/.

CNRR y GMH. (2011). La memoria histórica desde la perspectiva de género. Bogotá, Colombia: Pro-Offset.

CNM y UBC. (2013). "Recordar y narrar el conflicto”. Bogotá, Colombia: Imprenta Nacional de Colombia.

Defensoría del Pueblo. (2014). El conflicto armado y el riesgo para la mujer rural. Estudios de caso en los departamentos de Chocó, Córdoba, Santander y Caquetá. Recuperado de http: / / www.defensoria. gov.co/public/pdf/ElconflictoarmadoyelriesgoparalamujerruralDefensoriaONU2015. pdf 
Mujeres campesinas y construcción de paz territorial en Colombia: el caso de la asociación campesina del Valle del río Cimitarra (ACVC)

De Zubiría, S. (2016). Paz y territorios. Agencia Prensa Rural. Recuperado de http:/ / prensarural. org/spip/spip.php?article19323.

De Zubiría, S. (2017). Implementación desde los territorios. Revista Izquierda, 71, 5-11. Recuperado de http://www.espaciocritico.com/node/237\#dnld.

Dietz, M. (2003). Las discusiones actuales de la teoría feminista. Annual Review of Political Science, 6, 179-224. Recuperado de http://www.debatefeminista.cieg.unam.mx/wpcontent/uploads/2016/03/articulos/032_11.pdf

Fontan, V. (2013). Descolonización de la paz. Cali, Colombia: Editorial Universidad Pontificia Javeriana.

Galtung, J. (1996). Peace Theory. In J. Galtung. (Ed.), Peace and conflict, Development and Civilization (pp. 9-59). Oslo: International Peace Research Institute.

Guzmán, V. (2009). Reconstrucción filosófica de los estudios de paz. En J. Guzmán. (Ed), Filosofía para hacer las paces (pp. 61-74). Barcelona, España: Icaria Editorial.

Jiménez, F. (2012). Conocer para comprender la violencia: origen, causas y realidad. Revista Convergencia, 19 (58), 13-52. Recuperado de http://www.redalyc.org/articulo. oa?id=10520680001

Halbwachs, M. (1968). Memoria colectiva y memoria histórica. La memoria colectiva, 209-219. París, Francia: PUF.

Hernández, E. (2004). Resistencia civil artesana de paz. Experiencias indígenas, afrodescendientes y campesinas. Bogotá, Colombia: Editorial Pontificia Universidad Javeriana.

Ibarra, M.E. (2007). Acciones colectivas de las mujeres en contra de la guerra y por la paz en Colombia. Revista Sociedad y Economía, 13, 66-86. Recuperado de http://www.redalyc. org/pdf/996/99616721004.pdf.

Korol, C. (2016). Somos tierra, semilla, rebeldía. Mujeres, tierra y territorio en América Latina. Recuperado de https://www.grain.org/es/article/entries/5563-somos-tierra-semillarebeldia-mujerestierra-y-territorios-en-america-latina.

Jelin, E. (2002). Los trabajos de la memoria. Madrid, España: Siglo XXI Editores España S.A.

Longo, R. (2016). Mujeres Sin Tierra: un feminismo campesino y popular. Diálogo con Etelvina Masioli, dirigente del MST de Brasil. En C. Karol. y G. Castro. (Comps.), Feminismos Populares. Pedagogías Políticas (pp. 155-168). Bogotá, Colombia: La Fogata.

Páez, A. (2016). Mesas comunales por la vida digna de la región: una propuesta campesina de construcción de la democracia (tesis de maestría). Universidad Industrial de Santander, Santander, Colombia. 
Pinto, E. (2011). Que cante la gallina, no solo el gallo: memoria, mujeres y tierra. Revista de Trabajo Social, 13, 43-59. Recuperado de http://www.bdigital.unal.edu. co/29730/1/28362-101432-1-PB.pdf

Proceso de Mujeres del Magdalena Medio. (2006). Declaración política del primer encuentro de mujeres del Magdalena Medio. Recuperado de http://www.prensarural.org/ mujeres20060325.htm

Registro Único de Víctimas. (2019). Víctimas registradas. Recuperado de https://www. unidadvictimas.gov.co/es/registro-unico-de-victimas-ruv/37394

Rodríguez, C., Lorenzo, O. y Herrera, L. (2005). Teoría y práctica del análisis de datos cualitativos. Proceso general y criterios de calidad. Revista Internacional de Ciencias Sociales y Humanidades, 2, 133-154. Recuperado de http://www.redalyc.org/pdf/654/65415209. pdf.

Silva, D. (2011). Asociaciones Campesinas en Resistencia civil construcción de paz y desarrollo en el Magdalena Medio. Bogotá, Colombia: UNIMINUTO.

Silva-Prada, D. F. (2012). Organización de la comunidad en medio del conflicto social y armado. El caso de la Asociación Campesina del Valle del río Cimitarra. Cuadernos de desarrollo rural, 9, 17-40. Recuperado de http://www.scielo.org.co/pdf/cudr/v9n68/v9n68a02.pdf.

Suárez, I. (2017). Trayectorias de Dolor y Resistencia. Bucaramanga, Colombia: División de publicaciones UIS.

Todorov, T. (2000). Los abusos de la memoria. Barcelona, España: Paidós.

Torres, A. (2014). Hacer historia desde Abajo y desde el Sur. Bogotá, Colombia: Ediciones desde abajo. 